\title{
Aeromonas hydrophila as a Causative Agent of Fester-Needle Tail Disease in Guppies (Poecilia reticulata)
}

\author{
Yuxi Huang ${ }^{1 \dagger}$, Shibo Jin ${ }^{1 \dagger}$, Songzhe $\mathrm{Fu}^{2}$, Chunchun Meng ${ }^{3}$, Zhiqiang Jiang ${ }^{1}$, Shigen Ye ${ }^{1}$, Dazuo Yang ${ }^{1}$ and Ruijun $\mathrm{Li}^{{ }^{* *}}$ \\ ${ }^{1}$ Agriculture and Rural Affairs Ministry Key Laboratory of Mariculture \& Stock Enhancement in North China's Sea, Dalian \\ Key Laboratory of Marine Animal Disease Control and Prevention, College of Fisheries and Life Science, Dalian Ocean \\ University, Dalian 116023, China \\ ${ }^{2}$ College of Marine Technology and Environment, Dalian Ocean University, Dalian116023, China \\ ${ }^{3}$ Shanghai Veterinary Research Institute, Chinese Academy of Agricultural Sciences, Shanghai 200241, China \\ *For correspondence: liruijun@dlou.edu.cn; ruijunshine@gmail.com \\ ${ }^{\dagger}$ Contributed equally to this work and are co-first authors \\ Received 22 June 2020; Accepted 31 October 2020; Published 10 January 2021
}

\begin{abstract}
Nowadays, increases in the scale of guppy (Poecilia reticulata) breeding have been accompanied by increases in the frequency of disease, resulting in economic losses. One such disease, the fester-needle tail disease was notorious. In the current study, an epidemiological investigation was carried out for 1 year, and a total of 138 needle tail cases with obvious symptoms of rot were collected from 5 guppy farms in Anshan and Liaoyang cities in Liaoning Province, China. Microscopic observations excluded fungal and parasitic infections as causes of the disease. Transmission electron microscopy did not detect any viral inclusions in the diseased site. There was a high density of nucleiinthe cells, with cells becoming longer and narrower, and containing an increasing number of vesicles. In total, 232 bacterial strains were isolated from fish with needle tail disease. Results of 16S ribosomal DNA sequencing, and physiological and biochemical identification showed that Aeromonas spp. accounted for $35.3 \%$ of all the isolates, with Aeromonas hydrophila being the most isolated strain; in total 37 strains were isolated, accounting for $45.1 \%$ of the Aeromonas spp. isolates. A bacterial challenge experiment with A. hydrophila revealed it to be a possible causative agent of fester-needle tail disease. Histopathological observations in the controlled infection showed that epithelial cells in the caudal fin became more compacted, with all cells showing different degrees of karyotheca dissolution. These results provide a reference for further research and scientific control of needle tail disease in this economically important species. (C) 2021 Friends Science Publishers
\end{abstract}

Keywords: Aeromonas hydrophila; Histopathology; Needle tail disease; Poecilia reticulata

\section{Introduction}

Guppy (Poecilia reticulata; Cyprinodontiformes, Poeciliidae, Poecilia) is the main small ornamental fish of the freshwater aquaculture industry in China. In recent years, we have seen an annual increase in guppy production, accompanied by increase in disease, restricting the development of the ornamental fish industry. Common guppy diseases have included bacterial diseases caused by Aeromonas spp. (Chambel 2011) and Vibrio cholerae (Balakrishna 2013); parasitic diseases, such as ichthyophthiriasis, caused by Ichthyophthiriu smultifiliis (Chen 2002), Gyrodactyliasis spp. (Van-Oosterhout et al. 2007), and Tetrahymena pyriformis (Ponpornpisit et al. 2010); mycosis caused by fungi, such as Saprolegnia spp. (Qu 2009) and Aspergillus spp. (Haroon et al. 2014); and viral nervous necrosis (VNN), caused by nodaviruses
(Munday et al. 2002). Needle-tail disease has been a high incidence of disease with high mortality in guppies in recent years. The course of the disease is as follows: first, the opening angle of the caudal fin becomes smaller, sometimes with rotting tissue, and finally the fin merges into spicules, which may result in fish death. However, there are only a few reports of the etiology of needle tail disease from China or overseas area. Latremouille (2003) reported that fin erosion occurred when the fins of afflicted fish became degraded for a variety of reasons, including abrasion from rough surfaces, fin damage from aggressive encounters between fish, nutritional deficiencies, and bacterial infections (Latremouille 2003). Previous epidemiological investigations on needle tail disease in $P$. reticulata showed that guppy needle tail disease can be divided into two types, one caused by environmental stress and the second, which results in 'needle tails' after fin rot, which we refer to here as

To cite this paper: Huang Y, S Jin, S Fu, C Meng, Z Jiang, S Ye, D Yang, R Li (2021). Aeromonas hydrophila as a Causative agent of fester-needle tail disease in guppies (Poecilia reticulata). Intl J Agric Biol 25:397-403 
'fester-needle tail disease'. High ammonia concentration in aquatic environment can cause the occurrence of needle tail in $P$. reticulata but does not cause rotting of the caudal fins (Jin et al. 2019).

In the current study, the etiology of the fester-needle tail disease was explored further. We first investigated whether aquatic conditions, fungi, viruses, parasites, and other pathogens could be causative agents of the disease, and then ruled out those possibilities and finally we isolated the dominant bacteria. Bacteria isolated from diseased tissue were identified and their ability to cause fester needle tail disease was investigated in artificial infection experiments. The results of the current study support the division of needle tail disease into disease caused by aquatic conditions and disease caused by bacteria. Such information will be important for managing and controlling the impact of this disease on the future development of the guppy aquaculture industry.

\section{Materials and Methods}

\section{Guppies}

Healthy and diseased guppies, which had similar age and size (5 months old, $1.3-1.5 \mathrm{~cm}$ ) were collected from 5 guppy farms in Anshan and Liaoyang cities in Liaoning. An epidemiological investigation was carried out, and a total of 138 needle tail cases with obvious symptoms of rot were collected. The caudal fin of the diseased $P$. reticulate merged into spicules. After the experiment, the fishes were euthanized refer to the requirements of the Committee of Animal Welfare and Ethic at Dalian Ocean University.

\section{Ultrastructural observations}

The intact healthy and diseased $P$. reticulate were fixed with a volume fraction of $2.5 \%$ glutaraldehyde and then were sent to the Shanghai Veterinary Research Institute, Chinese Academy of Sciences for trans mission electron microscopy studies and ultrastructural observations.

\section{Isolation of pathogenic microorganisms}

The surface of diseased fish was disinfected with $75 \%$ alcohol and then rinsed three times with sterilized normal saline. Each caudal fin was removed in a sterile environment and placed in a $1.5 \mathrm{~mL}$ centrifuge tube containing sterilized pure water. Each caudal fin was ground to tissue homogenization by sterile medical tweezers and vortex mixer (Dragon Lab., China). A total of $100 \mu \mathrm{L}$ of homogenate was coated in nutrient agar (Hopebio, China) culture medium and inverted upside down at $28^{\circ} \mathrm{C}$ for 24 72 h. Any bacterial growth was observed and the dominant colonies which had the largest number were selected for purification by plate streaking according to their morphological characteristics.

\section{Identification of pathogenic microorganisms}

Each purified strain was inoculated in nutrient broth (NB) liquid medium and cultured in a shaking table at $28^{\circ} \mathrm{C}$ and $180 \mathrm{rpm}$ for $24 \mathrm{~h}$. Total bacterial DNA was extracted using a bacterial genomic DNA extraction kit (Tiangen, China). The extracted DNA was used as a template with the universal primers 27F (5'-AGAGTTTGATCCTGGCTCAG-3') and 1492R (5'-GGTTACCTTGTTACGACTT-3') (Lane 1991) to amplify the $16 \mathrm{~S}$ rDNA gene. The PCR reaction conditions were as follows: denaturation at $94^{\circ} \mathrm{C}$ for $10 \mathrm{~min}$; and then 30 cycles of denaturation at $94^{\circ} \mathrm{C}$ for $30 \mathrm{~s}$, annealing at $55^{\circ} \mathrm{C}$ for $30 \mathrm{~s}$, extension at $72^{\circ} \mathrm{C}$ for $1 \min 30 \mathrm{~s}$, plus a final extension step at $72^{\circ} \mathrm{C}$ for $10 \mathrm{~min}$. The PCR products were detected by $1 \%$ agarose gel electrophoresis, and then sent to Sangon Biotech Co. (Shanghai, China) for nucleic acid sequencing. The sequencing results were analyzed by using BLAST analysis in GenBank (https://blast.ncbi.nlm.nih.gov/Blast.cgi).

\section{Challenge infection}

The dominant bacteria were inoculated in NB liquid medium and placed in a flask on a constant temperature shaking table at $28^{\circ} \mathrm{C}$ at $180 \mathrm{rpm}$ for $24 \mathrm{~h}$. The concentration of bacteria was measured by using a bacterial chamber. After centrifugation, the supernatant was removed and the bacterial suspension was serially diluted to $1 \times 10^{6} \mathrm{CFU}$ $\mathrm{mL}^{-1}, 1 \times 10^{7} \mathrm{CFU} \mathrm{mL}^{-1}, 1 \times 10^{8} \mathrm{CFU} \mathrm{mL}^{-1}, 1 \times 10^{9} \mathrm{CFU} \mathrm{mL}^{-1}$, and $1 \times 10^{10} \mathrm{CFU} \mathrm{mL} \mathrm{m}^{-1}$ with normal saline.

Experimental and control groups were established with 40 healthy $P$. reticulate per group. The control group was soaked in $0.9 \%$ normal saline in a $1 \mathrm{~L}$ beaker for $1 \mathrm{~h}$ and then transferred to a clean $10 \mathrm{~L}$ aquarium. For each experimental group (one at each bacterial concentration), the fish were placed in $1 \mathrm{~L}$ beakers with either $1 \times 10^{6} \mathrm{CFU}$ $\mathrm{mL}^{-1}, 1 \times 10^{7} \mathrm{CFU} \mathrm{mL}^{-1}, 1 \times 10^{8} \mathrm{CFU} \mathrm{mL}^{-1}, 1 \times 10^{9} \mathrm{CFU} \mathrm{mL}^{-1}$,

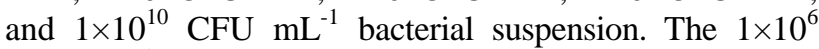
$\mathrm{CFU} \mathrm{mL} \mathrm{m}^{-1}$ bacterial suspension was deemed to be a safe concentration for $P$. reticulata, whereas the $1 \times 10^{10} \mathrm{CFU} \mathrm{mL}^{-1}$ bacterial suspension was deemed to be the most lethal concentration (being the lower and upper concentration limits). After soaking for $1 \mathrm{~h}$, the fish were transferred to a clean $10 \mathrm{~L}$ aquarium. The fish were observed continuously for at least 15 days and the morbidity and mortality rates were recorded. The fish were fed twice a day, with one-third of the water was changed every 5 days, and were provided with a continuous aeration supply.

\section{Histopathological analysis}

After 15 days of artificial infection, the caudal fins of each fish with needle tail disease and healthy fish in the control group were removed by sterile medical tweezers, placed into $4 \%$ paraformaldehyde and fixed at room temperature for $24 \mathrm{~h}$. The samples were then dehydrated through a 
graded ethanol series (50-100\%), cleaned in xylene, and embedded in paraffin wax. For staining, sectioned material was dewaxed in xylene, rehydrated through a graded ethanol series $(0-100 \%)$ and stained with hematoxylin and eosin. Permanent preparations were obtained by dehydrating (through an ethanol series 50 $100 \%$ ), and cleaned in xylene; neutral resin was used to seal the tissue sections, which were then examined under a Leica DM4000 microscope (Jin et al. 2020).

\section{Results}

\section{Ultrastructure observations of caudal fins of $P$. reticulate with needle tail disease}

An electron microscope was used to analyze histomorphological changes between the healthy and diseased tissues. The cells of healthy fish showed a normal density, were moderate in length, and contained no obvious vesicles (Fig. 1A, B). No virus-infected cells or virus inclusion bodies were found in the samples from the lesions of naturally infected $P$. reticulata. The nucleus and cytoplasm of diseased fish were both very dense, with elongated and narrower cells containing increased numbers of vesicles (Fig. 1C, D).

\section{Bacterial isolation and identification}

In total, $138 P$. reticulata with needle tail disease were collected. After isolating the bacteria from the diseased site, 232 strains were identified based on 16S rDNA molecular biological, physiological, and biochemical identification. Of the strains identified, Aeromonas spp. accounted for 35.3\% and Pseudomonas spp. accounted for $13.7 \%$ (Fig. 2). Aeromonas hydrophila accounted for $45.1 \%$ of the total Aeromonas isolates, indicating that it was the most dominant strain isolated from $P$. reticulata with needle tail disease.

\section{Artificial regression infection test}

After soaking respectively with a $1 \times 10^{6} \mathrm{CFU} \mathrm{mL}^{-1}, 1 \times 10^{7}$

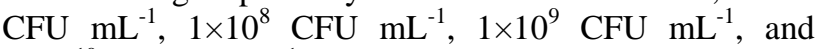
$1 \times 10^{10} \mathrm{CFU} \mathrm{mL}^{-1}$ concentration of $A$. hydrophila suspension, the mortality and needle tail infection rates of $P$. reticulata were recorded over 15 days (Fig. 4), and the deterioration process was showed in Fig. 3. In the control group, there were no $P$. reticulata with needle tail disease or mortalities. However, in all groups infected with $A$. hydrophila, both needle tail disease and mortalities of fish were recorded, as well as occurrences fin decay. With the increase in the concentration of $A$. hydrophila, the needle tail rate and mortality of $P$. reticulate were positively correlated. The mortality rate of the group with the highest concentration of $1.0 \times 10^{10} \mathrm{CFU} \mathrm{mL} \mathrm{mL}^{-1}$ was $100 \%$, with a needle tail rate of $55 \%$; the mortality rate of the group with the lowest concentration of $1.0 \times 10^{6} \mathrm{CFU} \mathrm{mL} \mathrm{mL}^{-1}$ was $75 \%$, with a needle tail rate of $30 \%$.

\section{Histopathological changes}

In the caudal fins of healthy $P$. reticulata, the fiber structure was arranged, and the pigment granules were visible (Fig. $5 \mathrm{~A})$; the muscle fibers were closely packed, with a distinct color hierarchy (Fig. 5C); epithelial histiocytes were arranged compactly, with clear delineation between cells (Fig. 5E). In contrast, the caudal fins of infected P. reticulata had rotted and the opening angle of the fins had become smaller. The cells were unevenly arranged and less compact, and the fiber structure had ruptured (Fig. 5B); the fins then began to become more needle-like in appearance, with less obvious cellular boundaries, and pigment granules were transformed and intensively distributed (Fig. 5D). In the caudal fins of healthy $P$. reticulata, the cells were oval, closely packed, with intact nuclei (Fig. 5G). In the rotting part of the caudal fins of infected $P$. reticulata, a few bacteria were visible (red thin arrow in Fig. 5F). Microscopically, the cells could be seen to be swelling and dissolving, with significant cavitation (red thick arrow), and fractured cytomembranes, with only a few cells showing any trace of a nucleus. At the nonulcerated part of the caudal fin of infected $P$. reticulata, elliptic cells were reduced, loosely arranged, and vacuoles and karyolysis were observed (red thin arrow, Fig. 5H).

\section{Discussion}

Needle tail disease does not have a single causative agent, but it is rather a disease syndrome. Previous research confirmed that high concentrations of ammonia in the aquatic environment could cause needle tail disease in $P$. reticulate (Jin et al. 2019). In the current study, numerous bacterial strains were isolated from the caudal fins of $P$. reticulate. Most dominantly strain was $A$. hydrophila. Then, Aeromonas veronii and Pseudomonas alcaligenes were 15.5 and $12.5 \%$ respectively. However, future studies will need to test whether the latter two species are also causative agents of needle tail disease. Thus, needle tail disease might not only a special disease be caused by the environment or by a particular bacterium, but is rather a syndrome; a similar situation is seen with Aeromona spunctata $f$. intestinalis, Aeromonas sobria, Edwardsiella tarda, and A. hydrophila, which all cause bacterial enteritis in fish (Zhang et al. 1998; Xuan 2018; Yang et al. 2018), and with Proteus mirabilis (Zhang and Sun 2019), A. hydrophila, A. sobria, Yersinia ruckeri (Shao 2017), Vibrio scophthalmi, and Vibrio alginolyticus (Ying et al. 2019), which can all cause bacterial septicemia in fish. Therefore, we refer to needle tails as a "syndrome" the disease.

A. hydrophila is an important pathogen of many aquatic animals, and can cause different symptoms in different cultured species. The genus Aeromonas not only can cause diseases of fish and other cold-blooded species, but also can cause a variety of infectious complications in both immunocompetent and immunocompromised humans, 

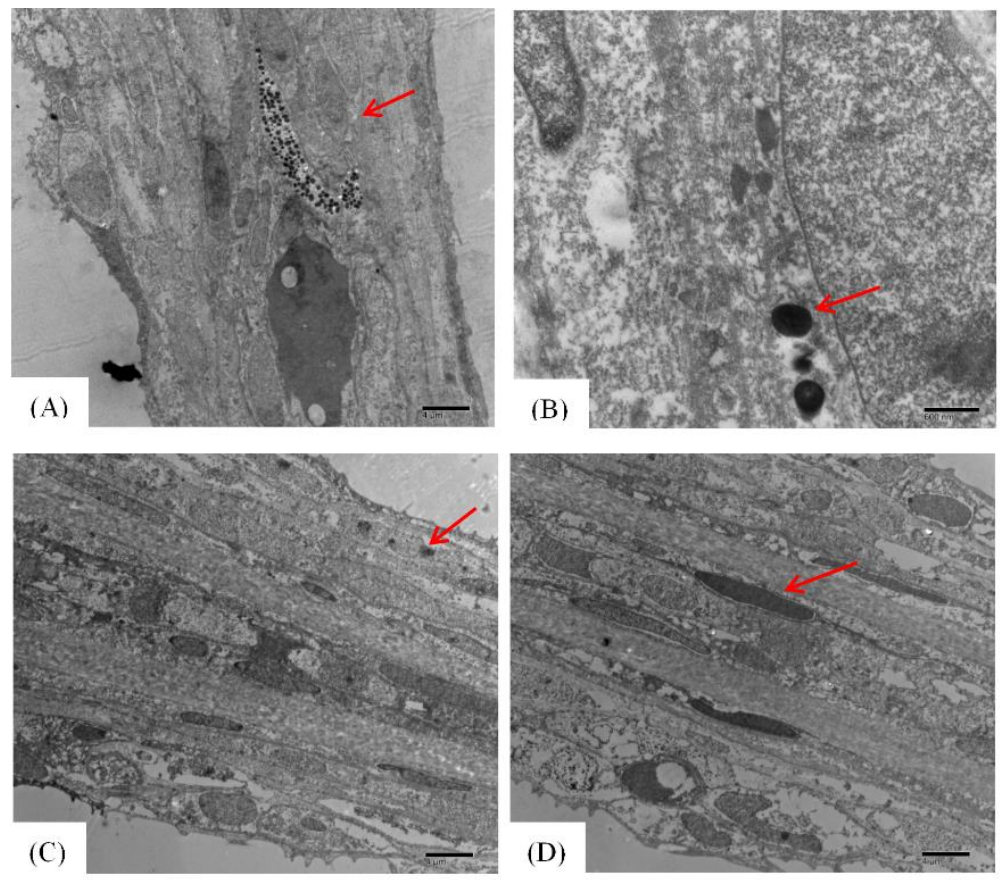

Fig. 1: Longitudinal sections of the caudal fin of healthy Poecilia reticulata $(\mathbf{A}, \mathbf{B})$ and of $P$. reticulata with needle tail disease (C, D). (A) No damage to the organelles (red arrow). (B) Cells are completely oval and contain no virus particles (red arrow). (C) Cell nuclei are pyknotic (red arrow). (D) There are no virus particles in the cells, which have become narrower (red arrow)
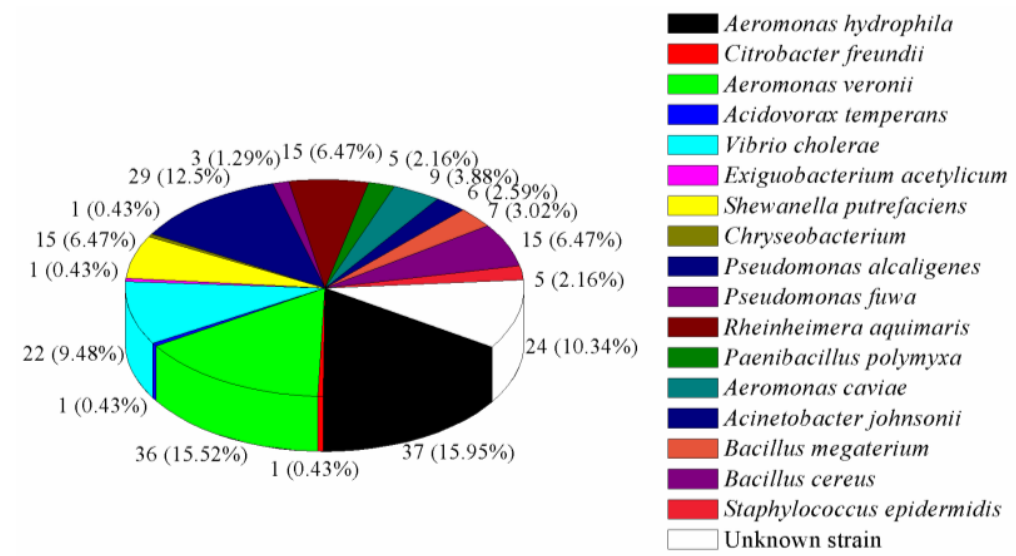

Fig. 2: Species identification of the 232 strains isolated from Poecilia reticulata with needle tail disease

therefore it is regarded as an important disease-causing pathogen (Janda and Abbott 2010). Aeromonas has also been reported as the main pathogen affecting freshwater ornamental fish (Martínezmurcia et al. 2008). The main pathogenic targets associated with Aeromonas are surface polysaccharides (capsule, lipopolysaccharide, and glucan), S-layers, iron-binding systems, exotoxins, and extracellular enzymes, secretion systems, fimbriae and other nonfilamentous adhesins, motility, and flagella (Tomás 2012). The level of virulence of different species of Aeromonas is not fixed, and depends on the bacterial strain, route of infection, and the animal used as a model organism (Yu et al. 2005). Chambel found that $P$. reticulata were sensitive to Aeromonas spp., especially A. hydrophila (Chambel 2011). Aeromonas is a thermophilic, motile bacterium that exists in fresh-water, sewage, silt, and soil, and is a primary pathogen that infects fish, amphibians, reptiles, and mammals (Zhang et al. 2001). The range of disease outcomes caused by A. hydrophila is broad, including motile septicemia in carp, tilapia, perch, catfish, and salmon; erythredema in weever fish and carp; and ulcerative infections in catfish, cod, carp and goby fish, including epiphytic ulcer syndrome (Holmes et al. 1996). It can also cause poisoning in eels (Austin et al. 1998). Research showed that carp infected with A. hydrophila became darker in color with fin ray hyperemia and fin decay 

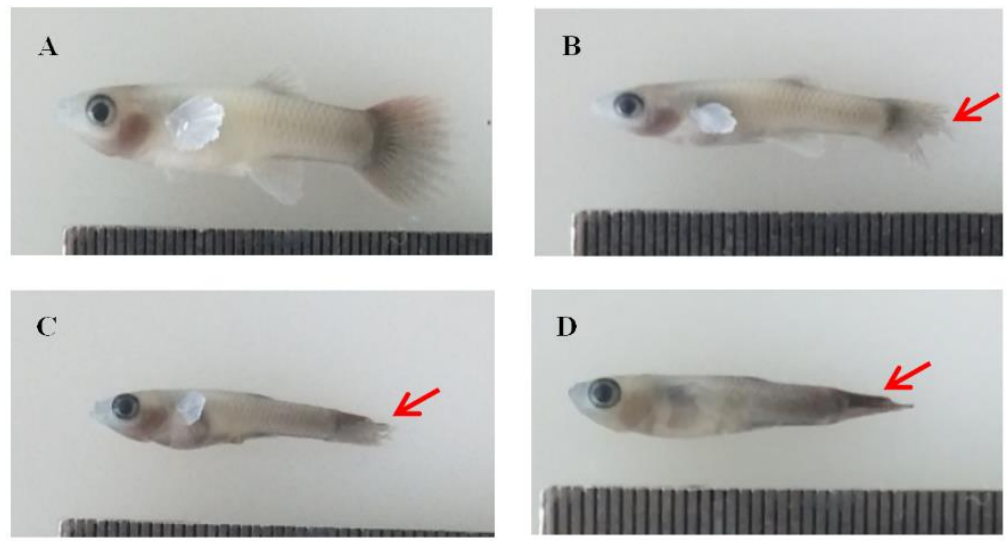

Fig. 3: The process of needle tail infection in Poecilia reticulata caused by Aeromonas hydrophila. (A) Healthy P. reticulata. (B) Caudal fin ulcer (red arrow). (C) Caudal fin ulcer and a reduced tail (red arrow). (D) Needle tail (red arrow)

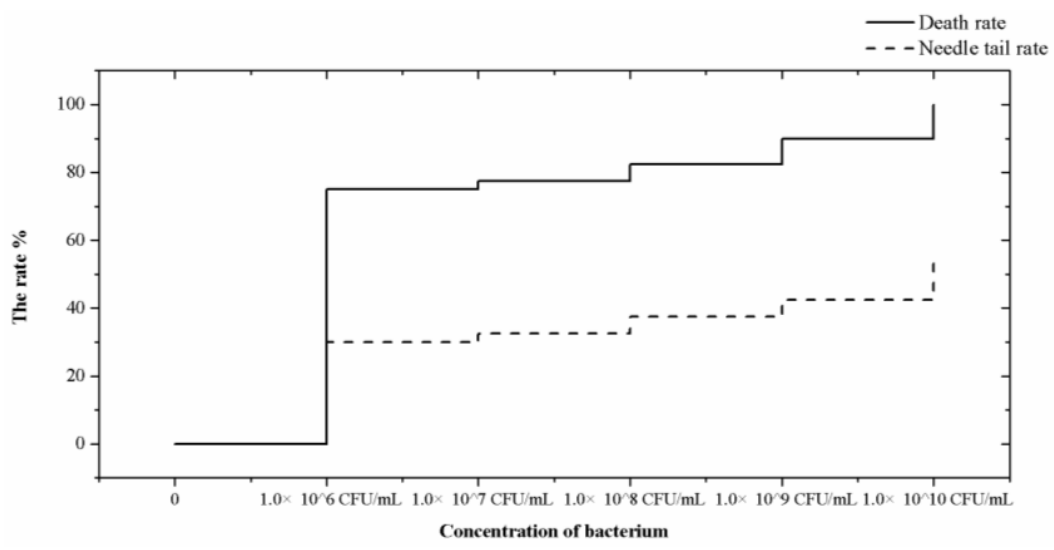

Fig. 4: The mortality and needle tail rates in Poecilia reticulata exposed to different concentrations of Aeromonas hydrophila

(Li et al. 2007). The caudal fins of hybrid tilapia were also reported to decay as a result of infection with $A$. hydrophila (Yang et al. 2009). Obvious characteristics of $A$. hydrophila infection in fish include hemorrhagic septicemia, fin rot, body swelling, and skin ulcers (Jacobs and Chenia 2007; Abolghait et al. 2010). Such features result mainly from the production by pathogenic A. hydrophila of hemolysins, enterotoxins, cytotoxins, and other extracellular enzymes, which result in red blood cell lysis, tissue cytolysis, and increased tissue permeability (Lu 1992). This study is the first to report that $A$. hydrophila infection of $P$. reticulata can lead to needle tail disease. However, how the infection causes the caudal fin to contract into a needle tail remains unclear; besides, whether the other bacteria which were largely isolated from diseased fins in the current study, like $A$. veronii and $P$. alcaligenes, also cause guppy needle tail disease, whether by the same mechanism as A. hydrophila, all will be carried out in further study.

The A. hydrophila that we isolated from naturally diseased guppies were relatively resistant to antibiotics and presents the trend of parallel propagation, according to our epidemiological investigation. Therefore, antibiotics might not be a suitable option for treating $P$. reticulata needle tail disease. In recent years, an increasing number of drugs against $A$. hydrophila has been developed. It has been reported that scutellaria baicalensis could affect the membrane permeability of A. hydrophila, causing intracellular ions and other molecules to exit the cell, destroying the integrity of the cell membrane, and resulting in its bacteriostatic effect (Wang et al. 2019). Morin can reduce the pathogenicity of $A$. hydrophila by inhibiting aerolysin, an important virulence factors secreted by this bacterium (Dong et al. 2019). Resveratrol can also affect type I and II gene expression of the quorum-sensing system in A. hydrophila, influencing downstream virulence correlation factors (Tan et al. 2019). Adding dietary fenugreek to fodder could enhance fish immunity and antioxidant capacities, reducing the visceral damage caused by A. hydrophila (Moustafaet al. 2020). It has also been reported that the inactivation of the nuclease (ahn) of $A$. hydrophila significantly impairs its ability to evade host immune attack (Ji et al. 2015). Thus, although A. hydrophila has strong pathogenic potential, its survival and reproduction strategies against the host immune system 


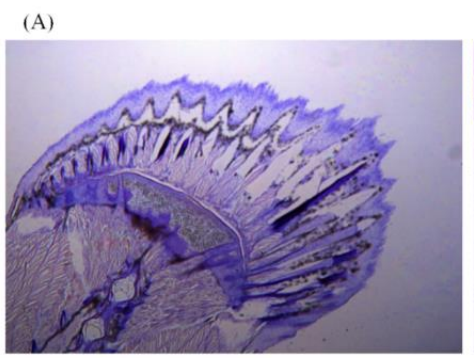

(C)

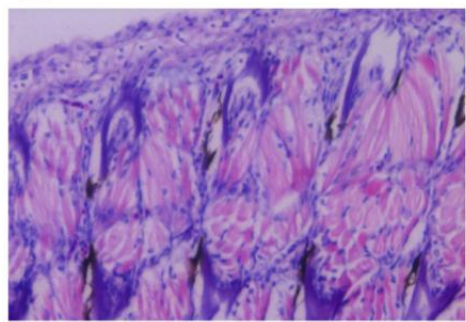

(E)

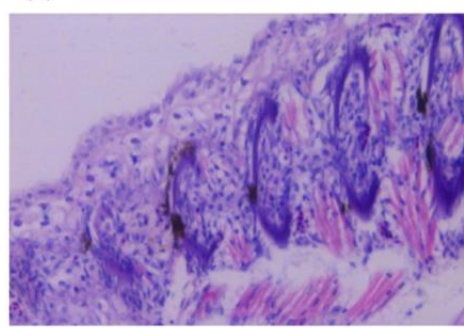

(G)

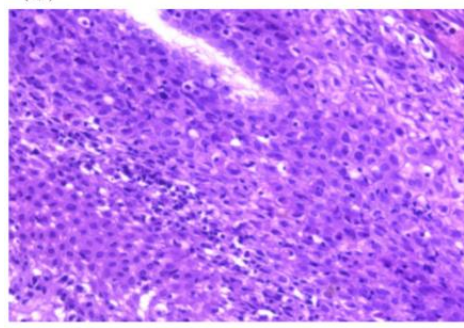

(B)

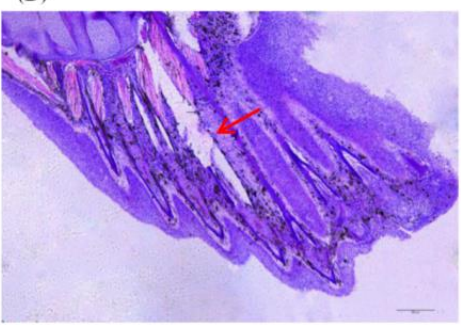

(D)

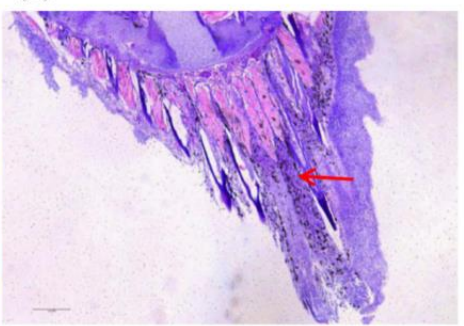

(F)

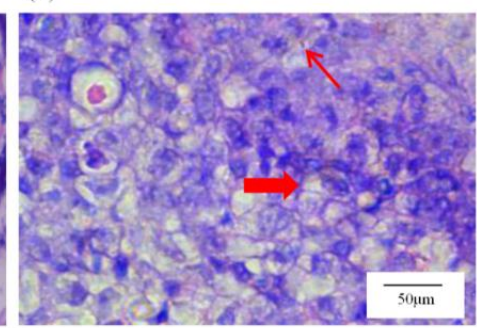

(H)

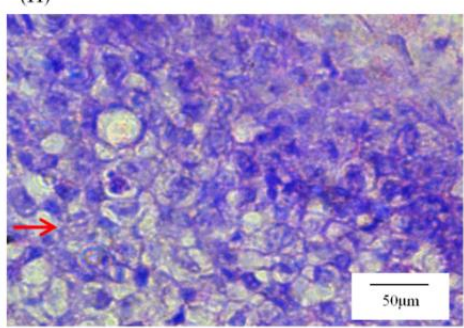

Fig. 5: Caudalfin of healthy Poecilia reticulata $(\mathbf{A}, \mathbf{C}, \mathbf{E}, \mathbf{G})$ and $P$. reticulata infected with Aeromonas hydrophila $(\mathbf{B}, \mathbf{D}, \mathbf{F}, \mathbf{H})$. The shrunken tail fin $(\mathbf{B})$ and needle tail fin of infected $P$. reticulata $(\mathbf{D})$. (F) Bacteria (red thin arrow) and cellular vacuolation (red thick arrow) and (H) karyolysis (red thin arrow) in infected $P$. reticulata

have yet to be fully determined (Citterio and Biavasco 2015) and, therefore, its prevention and control still require significant research attention. We hope other investigators reach more conclusive results than ours.

\section{Conclusion}

An epidemiological investigation of guppy fester-needle tail disease was carried out for 1 year. In total, 232 bacterial strains were isolated, and the A. hydrophila was the most isolated strain. A bacterial challenge experiment with $A$. hydrophila revealed it to be a possible causative eagent of fester-needle tail disease. These results provide a reference for further research and scientific control of needle tail disease in this economically important species.

\section{Acknowledgments}

This work was funded in part by the Nature Science Foundation Guidance Program of Liaoning Science and Technology Department (2019-ZD-0733), National Natural Science Foundation of China (41706177), International Cooperation Project of Liaoning Education Department (2019GJWYB20) and High-Level Talents Innovation Support Program of Dalian and support this work.

\section{Author Contributions}

YH performed the data analyses and wrote the manuscript; SJ conducted the epidemiological investigation and data analyses; SF made the identification of bacteria; $\mathrm{CM}$ dealt with the experiments of transmission electron microscope; 


\section{A. hydrophila Caused Fester-needle Tail Disease / Intl J Agric Biol, Vol 25, No 2, 2021}

ZJ, DY and SY performed the data analysis; RL designed and support this work.

\section{References}

Abolghait SK, Y Akeda, T Kodama, VV Cantarelli, T lida, T Honda (2010). Aeromonas hydrophila Pepo outer membrane endopeptidase activates human big endothelin-3 in vitro and induces skin ulcer in goldfish (Carassius auratus). Vet Microbiol 145:113-121

Austin B, DA Austin, I Dalsgaard, BK Gudmundsdóttir, S Høie, JM Thornton, JL Larsen, BO' Hici, R Powell (1998). Characterization of atypical Aeromonas salmonicida different methods. Syst Appl Microbiol 21:50-64

Balakrishna A (2013). In vitro evaluation of adhesion and aggregation abilities of four potential probiotic strains isolated from guppy (Poecilia reticulata). Braz Arch Biol Technol 56:793-800

Chambel MJ (2011). Comparação da sensibilidade de Danio rerio, Poecilia reticulata e Xiphophorus helleria Aeromonas hydrophila e Aeromonas aquariorum. Available at: http://iconlineipleiria.pre.rcaap.pt/handle/10400.8/585 (Accessed: 06June 2020)

Citterio B, F Biavasco (2015). Aeromonas hydrophila virulence. Virulence $6: 417-418$

Chen SX (2002). The breeding and disease control of guppy. Fish Sci Technol Inform 29:40-42

Dong J, YT Liu, N Xu, QH Yang, XH Ai (2019). The Molecular Mechanism of Morin Inhibits the Activity of Aeromonas hydrophila aerolysin. In: Proceedings of the $15^{\text {th }}$ symposium of veterinary pharmacology and toxicology branch of Chinese association of animal husbandry and veterinary medicine 27, Veterinary Pharmacology and toxicology branch of Chinese society of animal husbandry and veterinary medicine, Chinese Society of Animal Husbandry and Veterinary medicine

Haroon F, Z Iqbal, K Pervaiz, AN Khalid (2014). Incidence of fungal infection of freshwater ornamental fish in Pakistan. Intl J Agric Biol $16: 411-415$

Holmes P, LM Niccolls, DP Sartory (1996). The ecology of mesophilic Aeromonas in the aquatic environment. In: The genus Aeromonas, pp: 127-150. Austin B, M Altwegg, PJ Gosling, S Joseph (Eds.) John Wiley and Sons Ltd., West Sussex, England

Jacobs L, HY Chenia (2007). Characterization of integrons and tetracycline resistance determinants in Aeromonas spp. isolated from South African aquaculture systems. Intl J Food Microbiol 114:295-306

Janda JM, SL Abbott (2010). The Genus Aeromonas: Taxonomy, Pathogenicity, and Infection. Clin Microbiol Rev 23:35-73

Ji YC, JQ Li, ZD Qin, AH Li, ZM Gu, XL Liu, L Lin, Y Zhou (2015). Contribution of nuclease to the pathogenesis of Aeromonas hydrophila. Virulence 6:515-522

Jin SB, ZS Fu, RJ Li, HF Dang, DX Gao, SG Ye, ZQ Jiang (2020). Identification and histopathological and pathogenicity analysis of Aeromonas salmonicida salmonicida from goldfish (Carassius auratus) in North China. Aquacult Fish 5:36-41

Jin SB, ZQ Jiang, RJ Li (2019). Effects of ammonia nitrogen and pH on needle tail disease in guppies (Poecilia reticulata). Mod Agric Sci Technol 8:226-227

Lane DJ (1991). 16S/23SrRNA sequencing. In: Nucleic Acid Techniques in Bacterial Systematics, pp: 115-175. Stackebrandt E, M Goodfellow (Eds.). Wiley, Chichester, UK

Latremouille DN (2003). Fin erosion in aquaculture and natural environments. Rev Fish Sci 11:315-335
Li YH, PJ Zhang, WS Guo, YY Cui, X Wang (2007). Isolation, culture and identification of Aeromonas hydrophila. Proc 2007 Апnи Meet Jilin Anim Husb Vet Soc 11:165-170

Lu CP (1992). Pathogenic Aeromonas hydrophila and the fish diseases caused by it. J Fish Chin 16:282-288

Martínezmurcia AJ, MJ Saavedra, VR Mota, T Maier, E Stackebrandt, S Cousin (2008). Aeromonas aquariorum spp. nov., isolated from aquaria of ornamental fish. Intl J Syst Evol Microbiol 58:1169-1175

Moustafa EM, MAO Dawood, DH Assar, AA Omar, ZI Elbialy, FA Farrag, M Shukry, MM Zayed (2020). Modulatory effects of fenugreek seeds powder on the histopathology, oxidative status, and immune related gene expression in Nile tilapia (Oreochromis niloticus) infected with Aeromonas hydrophila. Aquaculture 515:734589

Munday BL, J Kwang, N Moody (2002). Betanodavirus infections of teleost fish: a review. J Fish Dis 25:127-142

Ponpornpisit A, MEndo, H Murata (2010). Experimental infections of a ciliate Tetrahymena pyriformis on ornamental fishes. Fish Sci 66:1026-1031

Qu WX (2009). The breeding and disease control of guppy. Heilongjiang Fish 134:22-23

Shao YD (2017). Prevention and treatment of bacterial septicemia in freshwater fish. Sci Fish Farm 4:91

Tan HL, K Chen, BW Xi, T Qin, LK Pan, J Xie (2019). Study on the effect of resveratrol on the toxicity of Aeromonas hydrophila. Acta Hydrobiol Sin 43:861-868

Tomás JM (2012). The main Aeromonas pathogenic factors. ISRN Microbiol 2012; Article 256261

Van-Oosterhout C, RS Mohammed, H Hansen, GA Archard, M McMullan, DJ Weese, J Cable (2007). Selection by parasites in spate conditions in wild Trinidadian guppies (Poecilia reticulata). Intl J Parasitol 37:805-812

Wang Y, BH Zhang, YM Lu, X Zhou, X Wang, LY Wang, XX He, H Liu (2019). Study on bacterioustatic activity and mechanism of Scutellaria baicalensis against Aeromonas hydrophila. J Shaanxi Univ Sci 37:73-78

Xuan JL (2018). Prevention and treatment of grass carp bacterial enteritis in Jinshan village, Beiwan town. J Trad Chin Vet Med 37:77

Yang KM, AM Guo, JX Ma, CR Duan, ZS Xie, C Yue (2018). Isolation, identification and drug susceptibility test of pathogenic bacteria in bacterial enteritis of perch (Perca fluviatilis Linnaeus). Progr Fish Sci 39:42-51

Yang N, ZY Xie, JH Huang, YC Zhou (2009). Isolation and identification of the pathogen of fulminant hemorrhages in hybrid tilapia (Oreochromis aureus $\times$ Oreochromis niloticus) cultured in Hainan. Nat Sci J Hainan Univ 27:43-47

Ying N, YQ Wu, B Qin, SG Wang (2019). The pathogenic diagnosis and drug control of bacterial septicemia of flounder. Sci Fish Farm11; Article 92

Yu HB, YL Zhang, YL Lau, F Yao, S Vilches, S Merino, JM Tomas, SP Howard, KY Leung (2005). Identification and characterization of putative virulence genes and gene clusters in Aeromonas hydrophila PPD134/91. Appl Environ Microbiol 71:4469-4477

Zhang HD, Y Sun (2019). The isolation and identification of pathogenic bacteria in bacterial septicemia of carp and drug susceptibility test. Fish Sci Technol Inform 46:332-337

Zhang XL, YM Wang, XQ Tang, MQ Wang (1998). Pathogen isolation and pathology research of Silurusmeria ionalis bacterial enteritis. Freshwater Fish 23:6-7

Zhang YX, Y Mu, GX Wang, XG Xu, JQ Li, XK Zhou, GZ Zou, YY Qi, WJ Yi (2001). Isolation and identification of Aeromonas hydrophila in fish. Chin J Prevent Vet Med 23:187-190 